\title{
Procedure Phases for Configuration SYSTEM DEVELOPMENT
}

\author{
Nemanja Sremčev ${ }^{\mathrm{a}}$, Ilija Ćosića ${ }^{\text {, Zoran Anišića }}$ \\ Milovan Lazarevića ${ }^{\mathrm{a}}$ Valentina Gechevska ${ }^{\mathrm{b}}$
${ }^{a}$ University of Novi Sad, Faculty of Technical Seciences, Trg Dositeja Obradovića 6, Novi Sad 21000, Serbia
${ }^{b}$ University Ss. Cyril and Methodius in Skopje, Faculty of Mechanical Engineering, Blvd. Goce Delcev 9, Skopje 1000, Republic of Macedonia

\begin{abstract}
One of the main characteristic trends of modern economic and production systems, no doubt, is the increase of product variety and the increase of different products offered by companies. At the same time, short delivery time or time to markets is a key factor for a company to win orders. More and more companies today rely on configuration systems in order to more efficiently and effectively meet customers' needs. The use of product configurators results in numerous benefits for manufacturing-oriented companies such as shorter lead time, less time for training new employees, fewer errors, etc. On the other hand, Group Technology (GT) is a manufacturing philosophy that identifies the similar attributes of product design and manufacturing processes. This paper aims to develop phases for product configurator development which is based on the principles of group technology. This procedure phases for configuration system development shows the stages that need to be completed by the company that wants to create its product configurator. Such companies can take advantage of the benefits offered by both, configuration system and group technology.
\end{abstract}

Keywords: configuration systems; group technology; configurator; mass customization
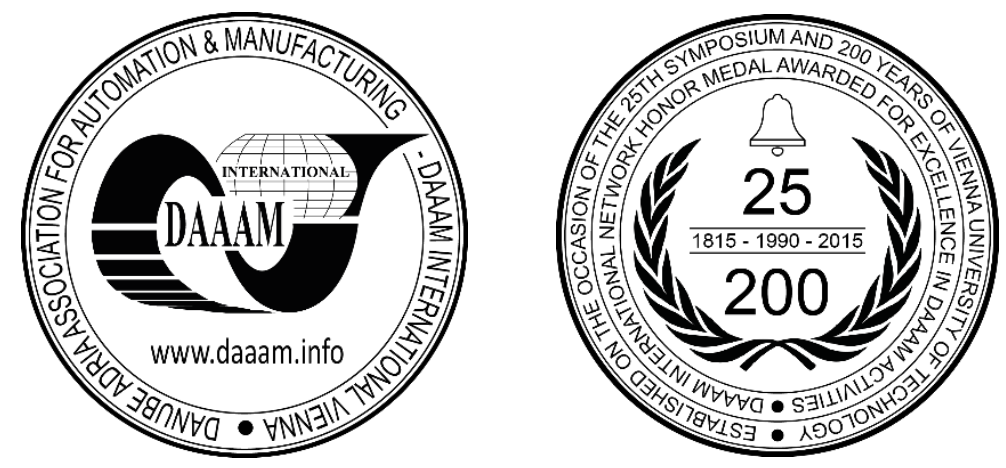

This Publication has to be referred as: Sremcev, N[emanja]; Cosic, I[lija]; Anisic, Z[oran]; Lazarevic, M[ilovan] \& Gecevska, V[alentina] (2016). Procedure Phases for Configuration System Development, Proceedings of the 26th DAAAM International Symposium, pp.0478-0482, B. Katalinic (Ed.), Published by DAAAM International, ISBN 9783-902734-07-5, ISSN 1726-9679, Vienna, Austria DOI: 10.2507/26th.daaam.proceedings.063 


\section{Introduction}

Today the market waits for no one. Companies need to rapidly respond to high variance of customer demands and enter the market in the shortest possible time with the model of the product, and in the end with product itself. Firms recognize that they need more time to come up with an offer, and while customers are becoming more demanding every day. The increase of product variety offered by enterprises is no doubt one of the main characteristic trends of modern economics systems. In spite of the homogenization of the individual needs and the liberalization of international trade, related to globalization, this trend is found in several areas.

In an effort to better respond to customers' requests and needs, many companies find it appropriate to increase the variance of their products, i.e. the variety of products that will be offered to potential customers. In doing so, companies are confident that in this way they increase the harmony between product offerings and customers' wishes, which allows them to define their market, and possibly increase their share in the market too. This conscious decision might enable companies to better align what they are offering with the market demands, however, such a decision brings many challenges for the company. The fact is that if the variance of the product increases, companies will be faced with lower efficiency for their internal activities. The problem is that there are no clearly defined activities that an entrepreneur should take to develop a product configurator in its own company. On the other hand, companies that have successfully implemented the configurator are unwilling to reveal their secret recipe and thus protect their competitive advantage.

Due to trends towards product proliferation and customization that have characterized many diverse industries [1][2][3], product configurators have increasingly drawn the attention of companies over the past few years. Product configurators represent one of the most successful applications of artificial intelligence principles[4][5]. Product configurators have been essential components of successful mass customization strategies in many firms, such as Dell Computers[6], Cisco Systems[7], American Power Conversion[8], or Reebok[9]. The academic community has promptly reacted to the heightened importance of product configurators for the business community, multiplying research initiatives aimed at studying this topic. Much of what has been written about product configurators has been from a technical or application development perspectives [10][11]. Many studies, for instance, have investigated how to improve the modeling of product configuration knowledge [12][13][14], or what algorithms make product configurators faster and more accurate [15][16].

In this paper, the integration of product configuration systems (also called configurators) and group technology is explored for mass customization environment. The basic idea is the development of a procedure for a product configurator build-up using the method of grouping similar parts/products (group technology). To this end, first, in Section 2, pertinent literature related to mass customization and configurators are reviewed, the types of the observed modularity are described and defined, and a brief overview of the Group Technology (GT) is given. In Section 3, the authors' procedure phases for the development of product configurators using GT are presented, while Section 4 ends with a conclusion.

\section{Literature review}

\subsection{Mass customization and configurators}

In the 1990s, the concept of mass customization first arose. This concept is based on the idea of satisfying large markets by combining the typical efficiency of mass production with ability to offer customized products that respond to customer specifications - the typical feature of tailored production, in other words, to reach an efficient variety in the presence of large volumes of production. For mass producers, to seek efficient variety means increasing product variety while maintaining efficiency[11][17].

The concept of a configuration system arose during the 1980s in connection with the development of a particular form of IT-based knowledge representation known as constrained based programming. In constraint-based programing a solution space is defined such as a series of modules in a product, and a number of constraints are defined for how these modules can be combined.

In the up growing race for faster product release and indulging the needs and wishes of customer centric market, design of products has become one of the most important steps in the product development [18]. Configurators support the configuration process, defined as the set of activities from the collection of information about customer needs to the release of the products documentation necessary to produce the requested product variant [10]. The sales configuration process includes all the activities carried out to identify the complete and congruent commercial description of the product that best fits customer requirements and it ends with the definition of the sales configuration. The sales configuration represents the description of the product the customer is willing to buy and the company agrees to supply. The technical configuration process includes all the activities that generate the documentation of the product variant, based on the sales description of the variant.

To configure means to put together a product from well-defined building blocks (modules) according to a set of pre-defined rules and constrains. In the next section the concept of modularity will be clarified. 


\subsection{Modularity}

Many scientists describe a module by saying that it is a limited part of the product with a well-defined function and a well-defined interface to the remaining parts (modules) of the product. The interface of the modules and the rules for how the various modules can be combined are defined. Figure 1, shows some of the main types of modularity[19].

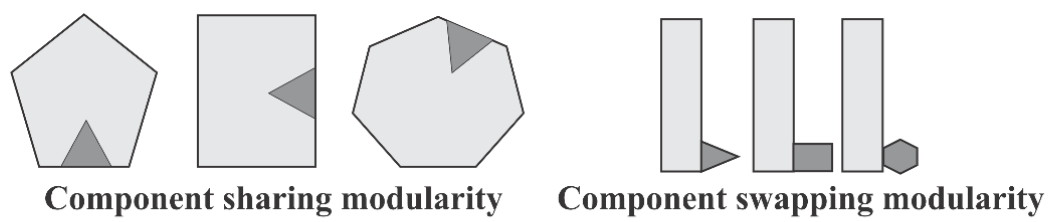

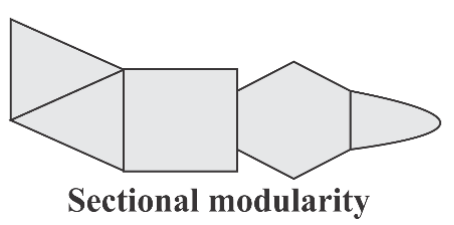

Sectional modularity

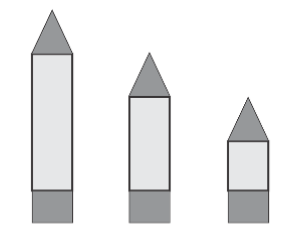

Cut-to-fit modularity

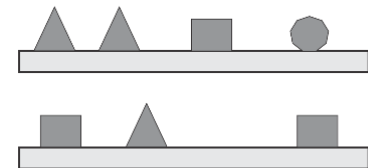

Bus modularity (platform)

Fig. 1. Types of modularity [19]

Component sharing modularity and component swapping modularity use the same components to span both product variants and product families. With sharing, the same components are used across product families, and with swapping, variants are introduced into a product family by adding small components. Cut-to-fit modularity has the property of parameterization, where some of the modules can be adapted by changing their dimensions. Sectional modularity means that modules can be combined freely, like Lego bricks, by exploiting the modules' interfaces. Bus modularity or platforms means that a platform is developed onto which components can be mounted. Platforms are used in the computer industry.

It should be noted that modularity research in design theory/engineering management has also been conducted for reasons unrelated to product variety. For example, research in this domain has sought to decompose complex design problems into more easily manageable sub-problems [20] or to investigate the impact on product performance [21]

\subsection{Group technology}

Group Technology (GT) has a great significance in the engineering industry [22]. GT provides a means to identify and exploit the similarities of parts and processes. Once identified, it is possible to capitalize on these similarities by processing together groups of similar parts. It appears that manufactured components can be classified into families similarly to biological families or library taxonomies. The part classified and grouped into families produce a much more tractable database for management [23].

Mitrofanov [24] first introduced the GT philosophy and the machine grouping problem in the late 1950s in the USSR. The other early pioneers in the field of GT are Burbidge and Ham. Burbidge classified the techniques as follows [25]: 1) Rules of Thumb techniques; 2) Classification and Coding techniques; 3) Production Flow Analysis (PFA) techniques. Ham classified the GT algorithms as follows [26]: 1) Peripatetic and ocular techniques; 2) PFA techniques; 3) Classification and Coding techniques; 4) Mathematical programming techniques.

The classification and coding techniques group parts on the basis of a number of attributes. As an example of such attributes one can list the shape of parts; dimensions of parts; material composition of parts; tolerance requirement and operations requirement. Typically, each part is assigned a ten to thirty digit code with each code representing an attribute of the part [27]. Depending on whether or not a hierarchical relationship exists, classification and coding systems have been classified as: hierarchical codes, non-hierarchical codes, and hybrid codes. On the other hand, the output of product flow analysis is a list of groups, list of machines and other facilities to be installed in each cell and list of the parts to be made in each cell [28].

\section{Procedure phases for development of product configurators using GT}

The procedure phases (Figure 2) are intended to help impose some structure on the task of developing and implementing a configuration system. By following this procedure it should be possible to: bring out the business requirements for a configuration system to be created; delimit and define knowledge which is to be incorporated into a configuration system; analyse and describe a complete product range and rules for designing a customer specific product; express product knowledge in an appropriate form for incorporation into a configuration systems, etc. 


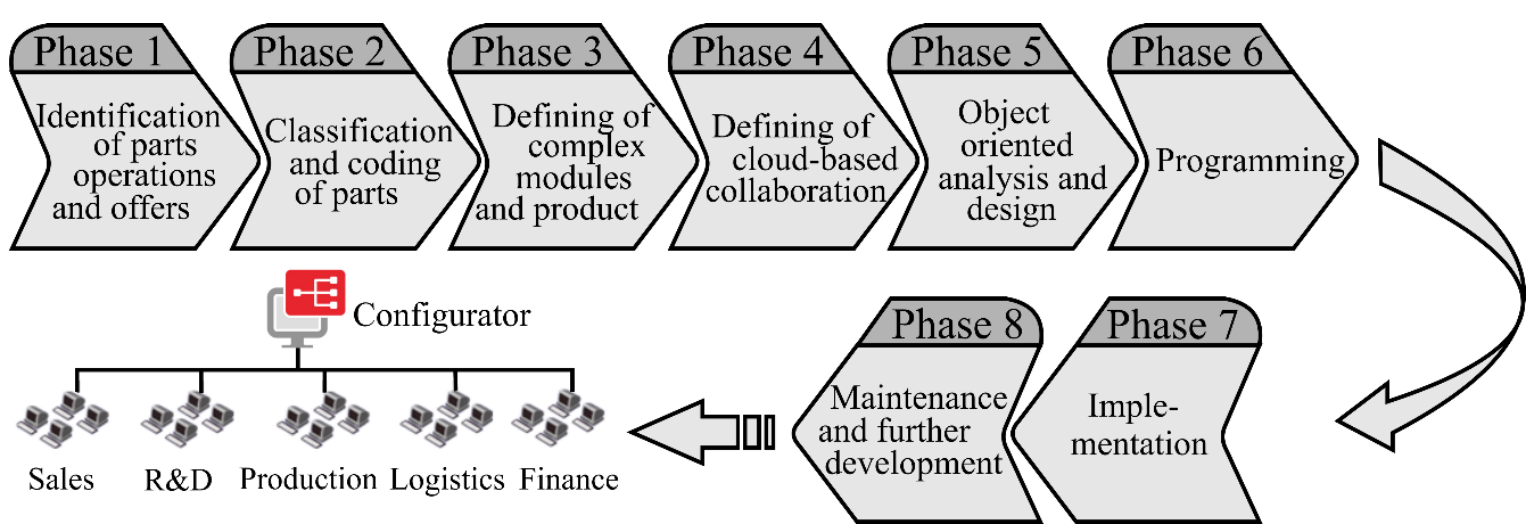

Fig. 2. Eight phases of procedure for developing configuration systems

The first phase of the procedure involves an analysis where the scope is to clarify the commercial aims of developing and implementing the configuration system. It is necessary to consider the opportunities that can be achieved in relation to the company's overall business strategy. The second phase consists of categorization of work pieces from manufacturing programs on the basis of their similarity - using the classification system. The classification criteria allows, on the basis of similar classification character, onto separate the group of work pieces which is suitable for the operations performing on the same machines or workplaces. Defining of complex modules and product is the third phase. The group of work pieces with the same or similar classification code constitutes the operational group on the basis of which complex module is defined. The complex module is the real or designed imaginary product or semi-product which has all the relevant characteristics of all parts from the operational group. In this phase, as well, the complex product is defined. The complex product, similarly to the complex module, has all the relevant characteristics of all complex modules (Figure 3).

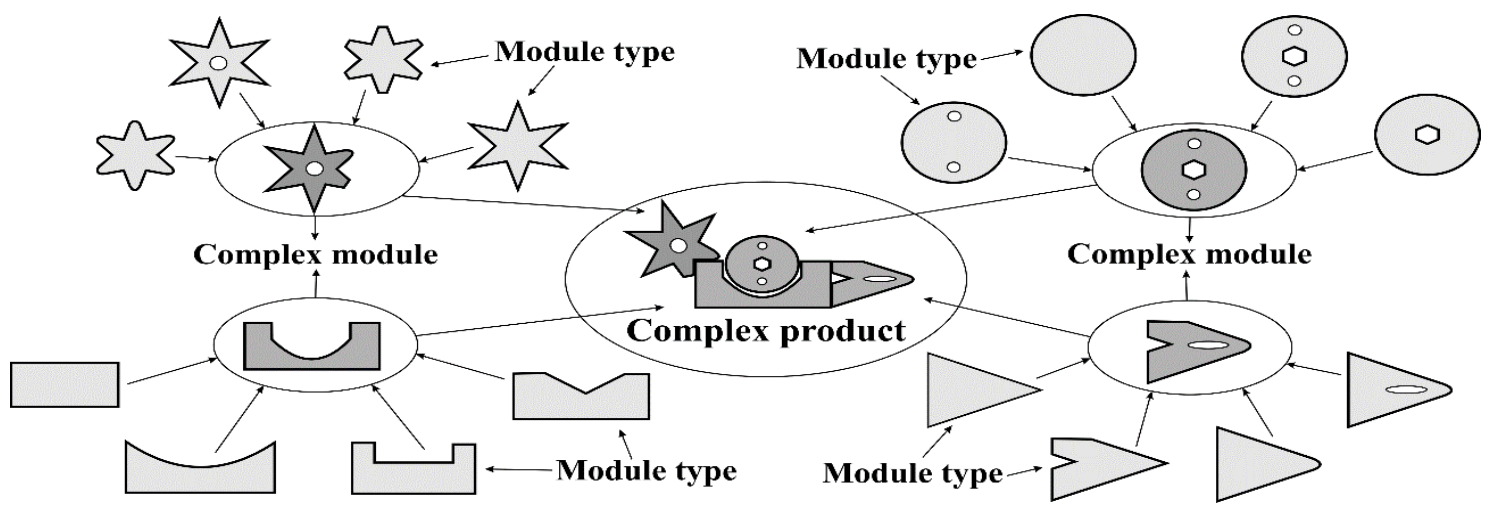

Fig. 3. Defining of complex product

The complex product consists of complex modules and a number of possible variants that are obtained by multiplying the number of possible variants for each of the complex modules. The next step is to define the technological process for a complex product with which this phase ends. In the fourth phase cooperation between workplaces (machining and assembly workplaces with the management of production) must be defined. All current tasks will be shared with all workplaces through configuration system and workers will have to sign in for work on a particular task.

The second part of the procedure starts with the fifth phase and object-oriented analysis and design. The aim of the fifth phase is to further develop the model (complex product) from the fourth phase, into a formal object-oriented model, which contains relevant knowledge about the product range and the configuration system, which can form the basis for the subsequent choice of software, adaptation of model and programming. The sixth phase is programming and an objected-oriented model can in principle be programmed in both an object oriented and a non-object oriented programming language. The seventh phase is the implementation of the system, and it is of decisive importance that the system's users accept the system. The last phase is maintenance and further development of implemented configuration system.

\section{Conclusion}

As can be seen from the presented procedure, the phases are not sharply separated. The work proceeds through the execution of a number of iterations. The use of the configuration system which has group technology principles in its core, leads to a number of improvements in the sale process as well as in production processes: the configuration systems enable the salesman to collects all the necessary information before a budgetary offer is sent to a potential customer; 
negotiation with the customer to have a better structure; the use of default values means that it is possible to make an early offer using very little input from the customer, thus the customer issues are answered more rapidly.

With principles of group technology, enshrined in the core of a configuration system, the time from the moment of forming an offer to the moment of delivery of the final manufactured product to the customer is shortened. Production therefore now has the task of making a complex product, for which they have developed a complex technological process and every variant of the product is one variant of the developed technological process. In this way, the result is: decrease of the passive set-up and interoperation times (3-12 times in total work times); simplification of the material and information flow; providing the operating plan execution to level of over $98 \%$ and higher suitability convenience for automation of technological system structure. Future work will be focused on implementing the proposed model in practice and testing the model's functionality.

\section{References}

[1] M. C. W. and R. Alm, “The right stuff: America's move to mass customization,” Annu. Rep., pp. 3-26, 1998.

[2] D. Sabin and R. Weigel, "Product configuration frameworks-a survey," IEEE Intell. Syst., 1998.

[3] B. L. Bayus and J. William P. Putsis, "Product Proliferation: An Empirical Analysis of Product Line Determinants and Market Outcomes," Mark. Sci., May 1999.

[4] M. Stumptner, "An overview of knowledge-based configuration," Ai Commun., 1997.

[5] A. Felfernig, G. Friedrich, D. Jannach, and M. Stumptner, "Consistency-based diagnosis of configuration knowledge bases," Artif. Intell., 2004.

[6] J. Magretta, “The Power of Virtual Integration: An Interview with Dell Computer's Michael Dell," 1998.

[7] M. Tseng and F. Piller, "The customer centric enterprise-advances in mass customization and personalization," 2003.

[8] L. Hvam, "Mass customisation in the electronics industry: based on modular products and product configuration," Int. J. Mass Cust., 2006.

[9] F. Piller, "Observations on the present and future of mass customization,” Int. J. Flex. Manuf. ..., 2007.

[10] C. Forza and F. Salvador, "Managing for variety in the order acquisition and fulfilment process: The contribution of product configuration systems," Int. J. Prod. Econ., vol. 76, no. 1, pp. 87-98, Mar. 2002.

[11] F. Salvador and C. Forza, "Configuring products to address the customization-responsiveness squeeze: A survey of management issues and opportunities," Int. J. Prod. Econ., vol. 91, no. 3, pp. 273-291, Oct. 2004.

[12] D. Yang, M. Dong, and R. Miao, "Development of a product configuration system with an ontology-based approach," Comput. Des., vol. 40, no. 8, pp. 863-878, Aug. 2008.

[13] T. SOININEN, J. TIIHONEN, T. MÄNNISTÖ, and R. SULONEN, "Towards a general ontology of configuration," AI EDAM, vol. 12, no. 04, pp. 357-372, Sep. 1998.

[14] A. Felfernig, G. Friedrich, and D. Jannach, "Conceptual modeling for configuration of mass-customizable products," Artif. Intell. Eng., 2001.

[15] S. Ong, Q. Lin, and A. Nee, "Web-based configuration design system for product customization,” Int. J. Prod. ..., 2006.

[16] X. Luo, Y. Tu, J. Tang, and C. K. Kwong, “Optimizing customer's selection for configurable product in B2C ecommerce application," Comput. Ind., vol.'59, no. 8, pp. 767-776, Oct. 2008.

[17] N. Suzić, B. Stevanov, I. Ćosić, Z. Anišić, and N. Sremčev, "Customizing Products through Application of Group Technology: A Case Study of Furniture Manufacturing," Strojniški vestnik - Journal of Mechanical Engineering, vol. 58, no. 12. pp. 724-731, 15-Dec-2012.

[18] Z. Anišić, I. Veža, N. Suzić, N. Sremčev, and A. Orčik, "IMPROVING PRODUCT DESIGN WITH IPS-DFX METHODOLOGY INCORPORATED IN'PLM SOFTWARE,” Tech. Gaz., vol. 20, no. 1, pp. 183-193, 2013.

[19] B. Pine, Mass customization: the new frontier in business competition. 1999.

[20] C. Y. Baldwin and K. B. Clark, Design Rules: The power of modularity. MIT Press, 2000.

[21] A. Kusiak, "Development of modular products," IEEE Trans. Components, Packag. Manuf. Technol. Part A, vol. 19, no. 4, pp. 523-538, 1996.

[22] I. Kuric, "Dynamic classification for CAPP systems based on group technology," Proc. Int. Conf. TMT, 2006.

[23] J. Novák-Marcinčin, "PREPARATION OF NC PROGRAMS BY GROUP TECHNOLOGY THEORY APPLICATION," tmt.unze.ba.

[24] S. Mitrofanov, "Scientific principles of group technology," 1961.

[25] J. L. Burbidge, "Production flow analysis," Prod. Eng., vol. 42, no. 12, pp. 742-752, Dec. 1963.

[26] I. Ham, "Introduction to group technology," 1976.

[27] D. M. Zelenovic, I. P. Cosic, D. N. Sormaz, and Z. D. Sisarica, “APPROACH TO THE DESIGN OF MORE EFFECTIVE PRODUCTION'SYSTEMS.,” Int. J. Prod. Res., vol. 25, no. 1, pp. 3-15, 1987.

[28] D. Lazarevic, I. Cosic, M. Lazarevic, A. Rikalovic, and N. Sremcev, "Application of Group Tools in Production of Printed and Laminated Cardboard Packaging for Total In-process Time Reduction," Procedia Eng., vol. 69, pp. 1381-1387, 2014. 